\title{
Nonlinear Tax Elasticities And Their Implications For The Structural Budget Balance
}

Charl Jooste, University of Pretoria, South Africa

Ruthira Naraidoo, University of Pretoria, South Africa

\begin{abstract}
Research on tax elasticities in South Africa mainly employs linear models and shows that taxes evolve symmetrically irrespective of the economic cycle. This study extends this research to show that taxes behave asymmetrically and nonlinearly during expansions and contractions. Estimated linear elasticities imply that a one percent expansion in the cycle increases personal income tax, corporate income tax and value added tax by 1.43, 2.52 and 0.99 percent, respectively. However, estimated nonlinear elasticities are significantly different. During an expansion, the above elasticities increase by 1.89, 2.76 and 2.17 percent, respectively while during a contraction phase these elasticities increase by 0.89, 0.88 and 0.82 respectively. This finding of low tax collection during economic contractions has important implications for fiscal sustainability and overall fiscal prudence in South Africa. The findings of high tax elasticities during expansions might explain the underestimation of revenue by the government.
\end{abstract}

Keywords: structural budget balance; tax elasticities; nonlinearity; smooth transition regression; autoregressive distributed lag

\section{INTRODUCTION}

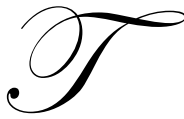

he global economy is faced with structural adjustments as financial markets fail. Large fiscal deficits incurred by governments during the financial crisis represented a coordinated effort by countries to save jobs and minimize the extent to which the economic growth declined. The G20 summit in March 2009 and the recent World Economic Forum at Davos in January 2010 announced that discretionary spending by most countries should exceed two percent of GDP.

Countries' economies are also responding in the form of automatic stabilizers where revenues fall and unemployment insurance increases, thus putting more pressure on the fiscal deficit. It is important that governments manage their fiscal deficits appropriately to avoid possible debt burdens. This study uses a measure of discretionary fiscal policy for South Africa to assess the fiscal stance during different phases of the economic cycle by explicitly testing for and using nonlinear tax elasticity adjustments.

This study also explores the asymmetric behaviour of revenues over the business cycle. In particular, a regime-switching framework is employed, where the transition from one regime to the other occurs in a smooth way. The switching between regimes is controlled by the state of output. This feature of the smooth transition model allows us to test the ability of high against low output regimes and to best describe the nonlinear dynamics of tax elasticities in the South African economy. In the case of South Africa, business cycle expansions and contractions can last as long as four years (see 2008q4 quarterly bulletin, s-159, for the duration of expansions and contractions), so the assumption that tax elasticities are of a short-term nature might be fallible. This paper proposes that long-term tax elasticities, as in the case of Du Plessis and Boshoff (2007), vary over the business cycle. To the best of our knowledge, this is the first attempt to model and compare across regimes the South African tax revenue 
relationship with respect to the business cycles using a non-linear model of fiscal adjustment. Using recursive and rolling estimates for the nonlinear regressions, this paper therefore contributes to a set of other studies in estimating the tax elasticities.

Our main finding is that the elasticities for various taxes are significantly different in regimes of economic expansions and contractions. Adjusting the structural budget balance for asymmetric effects is just an extension from using linear elasticities. It allows the policy maker to draw from a different set of analysing tools when setting the expenditure envelope based on forecasted revenue. The large elasticities during economic expansions provide a possible explanation for the underestimation of tax revenues.

\section{LITERATURE REVIEW}

The context of tax evolution in South Africa has undergone significant changes. South Africa has witnessed three government appointed commissions on aspects of the tax structure. These were the Franzsen commission in 1968, the Margo commission in 1987 and the Katz commission in 1994 (Black et al., 2005). As discussed in these commissions, South African authorities have, but for isolated events, implemented discretionary counter cyclical fiscal policy post 1994 due to adverse economic shocks. The South African economy has also gone through important tax reforms since the 1960s. Toward the end of the 1970s, indications that authorities were beginning to abandon counter cyclical policy arose in favour of longer term fiscal planning (Calitz in Black et al., 2005). Personal income tax no longer had strong automatic stabilizing effects due to bracket creep and tax rate adjustments.

Furthermore, the Treasury was under pressure to reduce government expenditure which limited its ability to either cool the economy off or stimulate it. In particular, a long cyclical downswing from 1989 to 1993 depressed tax revenues while social services raised government expenditure. Government revenue dropped from 25.1 percent of GDP in 1989/1990 to 21.7 percent in 1992/1993, while expenditures increased from 26.5 percent to 28.9 percent. The conventional budget deficit thus increased from 1.4 percent to 7.3 percent during that period, which resulted in higher debt of a peak of 50.4 percent to GDP in 1995. With a clearer focus on counter cyclical fiscal policy, the government was able to reduce the deficit from 2003 onwards, the result also being lower levels of debt (25 percent of GDP in 2008/2009). During the global economic slowdown in 2008 through to 2010, South Africa is once again faced with similar difficulties.

Tax revenues are highly dependent on business cycles. An expansion in a business cycle improves revenue collection as automatic stabilizers and people's willingness to pay taxes improves. However, when the economy is in a downturn, automatic stabilizers act conversely, people delay or simply cannot meet their tax obligations, which ultimately leads to a worsening of revenue collection. In terms of corporate income tax, companies can write off losses made in a current year, next year. Therefore, it is important to take note that revenue collections might not respond symmetrically to business cycles. Wolswijk (2007) argues that short-term elasticities sometimes exceed their long-run counterparts and often behave asymmetrically. The tax base may also remain stable regardless of the cycle, where revenue collected varies. A simple example of this would be wage rigidities present in South Africa's labour market, or specifically the inability to adjust wages down during an economic contraction. In theory, true long-term elasticities of taxes should be equal to unity. However, over the medium and short term, these elasticities can significantly exceed the "true" long-run estimates. A persistent economic expansion can shift consumption patterns to more luxury-based goods. The counter argument would seem that a contraction in the cycle will symmetrically shift this pattern. The problem with this statement lies specifically in the structure of South African households and firms. Spending patterns between various income groups are highly heterogeneous. Income inequality is another example of how taxes can respond asymmetrically over the cycle. When the economy enters a recession, it is the lower end of the labour market which bears the majority of lay-offs. However, most of income taxes come from the higher end of the income distribution where spending patterns might be more stable over the cycle. A final issue to consider is possible indirect effects of a change to a specific tax base relative to other bases. An example of this is higher company profits that lead to higher wages and ultimately higher levels of consumption.

Studies on tax elasticities for South Africa have received some attention due to the context of its economy. These studies focused primarily on linear estimation methods. Swanepoel and Schoeman (2002) estimate constant tax elasticities over the cycle. Their study shows that a one percent widening of the output gap results in a decrease of 0.2 percent in tax revenue. Du Plessis and Boshoff (2007) define the output gap in terms of a structural vector 
autoregression and estimate long-run elasticities for various taxes over the cycle. Their results show almost a one to one relationship for personal income tax, corporate income tax and value-added taxes over the cycle. Lizondo et al. (2006) find that taxes respond significantly differently than unity over changes in the economic cycle. This study marks a significant point of departure from previous papers in that it examines tax revenue/elasticity variations over business cycles. These estimates are then used to further adjust the budget balance. Government's conventional budgets reflect both temporary and permanent factors of the economy.

Failure to distinguish between the temporary and permanent factors can reduce the extent to which fiscal policy can intervene in times of recessions and save in times of economic expansions. Various measures analyze whether fiscal policy is sustainable over the cycle. One such measure is the structural budget balance (hereafter SBB). The SBB is the budget that would have prevailed once all cyclical components have been removed from the budget, or put differently, "it is the residual balance after purging the actual balance from the estimated budgetary consequences of the business cycle" (Hagemann, 1999:3). The calculation of the SBB involves estimating elasticities. Girourd and André (2005) estimate tax elasticities in the calculation of the SBB for OECD countries. They use OLS regressions to capture both marginal and average tax rates where the product of the two yields tax elasticities over the economic cycle.

\section{METHODOLOGY}

The structural budget balance (SBB) is defined as that component of the budget that depends on the long term trend of the economy, as represented by the long run path of output. This underlying path is subjected to permanent and temporary shocks (as is in the case of Blanchard and Quah, 1989). Technological shocks have a lasting impact over time, whereas transitory shocks dissipate over time, resulting in cyclical movements of actual output around potential output (Lizondo, 2006). "Failure to distinguish between temporary and permanent influences on the budget may cause fiscal levers to be over or under adjusted in response to budgetary developments" (Hagemann 1999:3). If fiscal policy is unchecked in this regard, it can lead to an accumulation of debt and become a form of fiscal dynamic time inefficiency (intended fiscal policy that is geared to be counter cyclical, but because of red tape and policy lags, becomes pro cyclical, which reduces the credibility of overall fiscal policy).

This paper only adjusts for cyclical revenues and assumes that fiscal expenditures are exogenous to the cycle. Except for the unemployment insurance fund (UIF), expenditures are seen as purely discretionary. UIF constitutes a small component of fiscal expenditures and is thus left unadjusted.

Formally, the SBB is derived as follows:

$$
b^{*}=\left[\left(\sum_{i=1}^{6} T_{t, i}^{*}\right)-G_{0}+X_{t}\right] / y_{t}^{*}
$$

where

$T_{t, i}{ }^{*}=T_{t, i}\left(\frac{y_{t}^{*}}{y_{t}}\right)^{\varepsilon_{t, y}}$

$y_{t} *$ is potential output

$y_{t}^{*}$ is observed output

$T_{t}^{*}$ is the cyclically adjusted tax for the various taxes

$G 0$ is unadjusted government expenditure

$X_{t}$ is nontax revenue minus capital and net interest spending

$\varepsilon_{t, y}$ is the estimated revenue elasticity regarding the cycle

The basic identity (equation 1) states that the SBB equals tax revenue adjusted for the economic cycle less government expenditures expressed as a percent of potential GDP and non-tax revenue as a percent of GDP. The tax revenue is adjusted for the cycle by incorporating a measure of average and marginal taxes through the estimated elasticities. 
Instead of estimating cyclical revenues for all the taxes, this study mainly focuses on the three major revenues; namely, personal income tax (PIT), corporate income tax (CIT) and value-added taxes (VAT), which constitute eighty percent of all taxes.

The output gap is defined as the difference between observed output from potential output. Potential output is derived using a structural vector autoregression (SVAR) as in Du Plessis, Smit and Sturzenegger (2007). To be robust, this study also uses the Hodrik Prescott filter to measure the output gap. The SVAR approach has the advantage of not assuming that potential GDP is a function of some statistical property, but rather a function of the underlying economy. Potential GDP is then a function of fiscal expenditure as a percent of GDP and real interest rates.

Following Girourd and Andre (2005), the respective elasticities, where the elasticity of taxes (PIT, CIT and VAT) over the cycle is derived, are as follows:

$$
\begin{aligned}
\varepsilon_{t_{i}, y}=\rho_{t b_{j}}^{t_{i}} \rho_{y}^{t b_{j}} & \text { for } i=\mathrm{PIT}, \text { CIT and VAT } \\
& \text { for } j=\text { wage bill, profits and consumption }
\end{aligned}
$$

Where:

$\varepsilon_{t_{i}, y}=$ total elasticity of tax revenue to the output gap.

$\rho_{t b_{i}}^{t_{i}}=$ the elasticity of the different taxes with respect to the various tax bases (first step).

$\rho_{t b}^{y_{i}}=$ the elasticity of the various tax bases with respect to the output gap (second step).

The reduced form elasticities combine tax contributions relative to the output gap by combining estimates of tax proceeds to changes in the tax base with estimates of the sensitivity of the tax base to the cycle (Girourd and André, 2005). They are then defined as follows:

The elasticity for PIT is defined by:

$$
\varepsilon_{\mathrm{t}, \mathrm{y}}=\left(\frac{\partial \mathrm{T}}{\partial \mathrm{Y}}\right) \frac{\mathrm{Y}}{\mathrm{T}}=\left(\partial\left(\left(\frac{\mathrm{T}}{\mathrm{L}}\right) \mathrm{L}\right) / \partial \mathrm{Y}\right) \frac{\mathrm{Y}}{\mathrm{T}}=\left(\partial\left(\left(\frac{\mathrm{T}}{\mathrm{L}}\right) \mathrm{L}\right) / \partial \mathrm{W}\right) \frac{\mathrm{W}}{\mathrm{T}}\left(\frac{\partial \mathrm{W}}{\partial \mathrm{Y}}\right) \frac{\mathrm{Y}}{\mathrm{W}}=\rho_{\mathrm{wl}}^{\mathrm{t}}, \rho_{\mathrm{wl}}^{\mathrm{y}}
$$

where $\varepsilon_{t, y}$ is the elasticity of personal income tax with respect to the output gap, $\varepsilon_{\mathrm{t}, \mathrm{wl}}$ is the elasticity of personal income tax to the wage bill, where w is the wage rate and 1 is employment, and $\varepsilon_{w l, y}$ is the elasticity of the wage bill to the output gap.

The elasticity for CIT is defined by:

$\varepsilon_{\mathrm{t}, \mathrm{y}}=\left(\frac{\partial \mathrm{T}}{\partial \mathrm{Y}}\right) \frac{\mathrm{Y}}{\mathrm{T}}=\left(\frac{\partial \mathrm{Z}}{\partial \mathrm{Y}}\right) \frac{\mathrm{Y}}{\mathrm{Z}}=(\partial(\mathrm{Y}-\mathrm{WL}) / \partial \mathrm{Y}) \frac{\mathrm{Y}}{\mathrm{Z}}=\left(1-\left(1-\left(\frac{\mathrm{Z}}{\mathrm{Y}}\right)\right)\left(\left(\frac{\partial \mathrm{WL}}{\partial \mathrm{Y}}\right) \frac{\mathrm{Y}}{\mathrm{WL}}\right)\right) \frac{\mathrm{Y}}{\mathrm{Z}}=\frac{(1-(1-\mathrm{PS})) \rho_{\mathrm{wl}}^{\mathrm{y}}}{\mathrm{PS}}$ 
where $\varepsilon_{t, y}$ is the elasticity of corporate income tax with respect to the output gap, PS is the profit share in GDP, Z is the gross operating surplus and $\rho_{\mathrm{wl}}^{\mathrm{y}}$ is the elasticity of the wage bill to the output gap; i.e., one can calculate the elasticity of corporate income tax with the following formula: $\frac{(1-(1-\mathrm{PS})) \rho_{\mathrm{wl}}^{\mathrm{y}}}{\mathrm{PS}}$

The elasticity for VAT is defined by:

$\varepsilon_{\mathrm{t}, \mathrm{y}}=\frac{\partial \mathrm{T}}{\partial \mathrm{Y}} \frac{\mathrm{Y}}{\mathrm{T}}=\left(\left(\frac{\partial \mathrm{V}}{\partial \mathrm{Y}}\right) / \partial \mathrm{Y}\right) \frac{\mathrm{Y}}{\mathrm{V}}=\left(\left(\frac{\partial \mathrm{V}}{\partial \mathrm{Y}}\right) / \frac{\mathrm{Y}}{\mathrm{V}}\right) /\left(\left(\frac{\partial \mathrm{Cs}}{\partial \mathrm{Y}}\right) / \frac{\mathrm{Y}}{\mathrm{Cs}}\right)=\rho_{\mathrm{cs}}^{\mathrm{t}}, \rho_{\mathrm{cs} 1}^{\mathrm{y}}$

where $\varepsilon_{t, y}$ is the elasticity of value-added tax with respect to the output gap, $\rho_{\mathrm{csl}}^{\mathrm{t}}$ is the elasticity of value-added tax to consumption and $\rho_{\mathrm{csl}}^{\mathrm{y}}$ is the elasticity of consumption to the output gap. V is VAT and Cs refers to the tax base, which is consumption.

Preliminary analysis, using standard Augmented Dickey Fuller tests, suggests that the tax and tax base variables are $I(1)$, as summarized in Table 1. This paper compares elasticities to that of Du Plessis and Boshoff (2008), Swanepoel and Schoeman (2002) and Jooste (2009). The regression techniques used by these authors are all different. Du Plessis and Boshoff (2008) estimate long-run tax elasticities using a VAR. Swanepoel and Schoeman (2002) estimate their elasticities with standard OLS regressions whereas Jooste (2009) uses a Vector Error Correction Model (VECM) to estimate the reduced form elasticities. This paper, however, uses the term mediumterm elasticity as opposed to long-run elasticities since the latter should, in theory, be close to one.

Table 1: Stationarity Tests

\begin{tabular}{|c|c|c|c|c|c|c|}
\hline \multicolumn{7}{|c|}{ ADF tests in levels (P values) } \\
\hline PIT & CIT & VAT & Wage bill & Profits & Consumption & Output gap \\
\hline 0.661 & 0.222 & 0.636 & 0.854 & 0.213 & 0.798 & 0.086 \\
\hline \multicolumn{7}{|c|}{ ADF tests in differences (P values) } \\
\hline 0.000 & 0.001 & 0.003 & 0.019 & 0.641 & 0.083 & 0.218 \\
\hline
\end{tabular}

This paper departs from the previous studies by sidestepping the proposed two-step approach ${ }^{1}$ and employs a framework using the smooth threshold regressive (STR, henceforth), which is a variant of the smooth threshold autoregressive (STAR) model, as proposed by Granger and Terasvirta (1993) and van Dijk et al. (2002). This model is an extension to the threshold autoregressive (TAR) model, as originally proposed by Tong and Lim (1980), in that the transition from one state to another is smooth rather than discrete.

Since the aim of the paper is to estimate the medium and short-term elasticities over the different phases of the cycle, it has to ensure that variables are stationary in the STR model (in our case, taxes and respective bases are $I(1)$ variables). Differencing the variables yields inconclusive results. Also faced with the problem of estimating an $\mathrm{I}(0)$ variable, the output gap, with I(1) variables, it is natural to extend the STR model in incorporating it into an autoregressive distributive lag model of order $\mathrm{p}$ and $\mathrm{n}, \operatorname{ARDL}(\mathrm{p}, \mathrm{n})$. The ARDL sets $\mathrm{p}=1$ and $\mathrm{n}=1$ on the basis of the Akaike Information Criterion. The ARDL model has the advantage of establishing long-run relationships, irrespective of whether variables are integrated of order 1 or 0 and is defined as:

\footnotetext{
${ }^{1}$ Girourd and André (2005 estimate two elasticities, one regarding taxes to the tax base and the other regarding the tax base to the output gap.
} 
$T_{t}=\sum_{i=1}^{p} b_{i}+\sum_{i=1}^{p} a_{i} T_{t-1}+\sum_{i=0}^{n} c_{i}^{\prime} T B_{t-1}+\varepsilon_{t}$

where $T$ refers to the tax and $T B$ to the tax base. Pesaran and Shin (1998) then used a variant of the standard ARDL equation for cointegration where $T$ is related to contemporaneous $T B$, differenced $T B \mathrm{~s}$ and lagged $T$ :

$T_{t}=\sum_{i=1}^{p} a_{i} T_{t-1}+a(1) \beta^{\prime} T B_{t}-\sum_{i=0}^{n-1}\left(\sum_{j-i+1}^{n} c^{\prime}\right)_{j}^{\prime} \Delta T B_{t-i}+\varepsilon_{t}$

A further variant relates $T$ to $T B$ and differences in both variables and renders the error correction term $\left(\hat{\gamma} \mathrm{T}_{\mathrm{t}-1}\right)$ as in Wickens and Breusch (1988):

$\Delta T_{t}=\hat{c}+\hat{\lambda} T_{t-1}+\hat{\theta}^{\prime} T B_{t-i}+\sum_{i=1}^{p} \alpha_{i} \Delta T_{t-i}+\sum_{i=0}^{n} \hat{\phi}^{\prime} \Delta T B_{t-i}+\varepsilon_{t}$

where the long-run estimate is calculated as:

$\hat{\beta}=-\frac{\hat{\theta}}{\hat{\lambda}}$

In establishing whether cointegration is present, Hasser and Wolters (2006) run Monte Carlo simulations and show that Banerjee et al's. (1998) suggestion of using the conventional student t-test is just as powerful as Boswijk's (1994) suggested F-test. Next, the ARDL version is augment STR model. This allows us to study the dynamics of taxes over the cycle where it relates to the tax base. This side steps the estimation method proposed by Girourd and André (2005) where one has to estimate two elasticities, to estimating it directly. The standard STR model for the nonlinear tax elasticities can be defined as follows:

$$
\Delta T_{t}=\psi^{\prime} z_{t}+\omega^{\prime} z_{t} G\left(\gamma, c, s_{t-d}\right)+\xi_{t}
$$

where $\mathrm{Z}_{\mathrm{t}}=\left(1, \Delta \mathrm{TB}_{\mathrm{t}-1} ; \mathrm{X}_{1, \mathrm{t}}, \ldots, \mathrm{X}_{\mathrm{m}, \mathrm{t}}\right)^{\prime}$ is the vector of explanatory variables, with $h=n+2+m$. The parameters $\psi=\left(\psi_{0}, \psi_{1}, \ldots, \psi_{h}\right)^{\prime}$ and $\omega=\left(\omega_{0}, \omega_{1}, \ldots, \omega_{h}\right)^{\prime}$ represent $\left((h+1)^{*} l\right)$ parameters in the linear and nonlinear parts of the model, respectively. The disturbance term is assumed to be identically and independently distributed with zero mean and constant variance, i.e. $\xi_{t} \sim \operatorname{iid}\left(0, \sigma^{2}\right)$. The transition function $G(\gamma, c, s)$ is assumed to be continuous and bounded in the transition variable $s_{t}$ (i.e., the output gap). In $S_{t-d}$, d is defined as lags $1,2, \ldots, \mathrm{T}$. As $s_{t} \rightarrow-\infty, G\left(\gamma, c, s_{t}\right) \rightarrow 0$ and as $s_{t} \rightarrow+\infty, G\left(\gamma, c, s_{t}\right) \rightarrow 1$. Our nonlinear function approximates a smooth logistic function where $G(\gamma, c, s)$ is modelled as follows:

$$
G\left(\gamma, c, s_{t}\right)=\left[1+\exp \left\{-\gamma\left(s_{t}-c\right)\right\}\right]^{-1}, \gamma>0
$$

This transition function is a monotonically increasing function of $s_{t}$, where the slope parameter indicates the smoothness from one transition to another. The location parameter $c$ determines where the transition occurs. Furthermore, the STR model is equivalent to a linear model with stochastically time varying coefficients and can be written as: 


$$
\Delta T_{t}=\left[\psi^{\prime}+\omega^{\prime} G(\gamma, c, s)\right] z_{t}+\xi_{t} \Leftrightarrow \Delta T_{t}=v^{\prime} z_{t}+\varepsilon_{t} \quad t=1, \ldots, T
$$

Given that $G(\gamma, c, s)$ is bounded between 0 and 1 , the combined parameters, $v$, will fluctuate between $\psi$ and $\psi+\omega$ and change monotonically as a function of $s_{t}$. The more the transition variable moves beyond the threshold, the closer $G(\gamma, c, s)$ will be to one and the closer the parameters $v$ will be to $\psi+\omega$. The further $s_{t}$ approaches the threshold, c, the closer the parameters $v$ will be to $\psi$.

To augment our ARDL model with the STR methodology we proceed as follows:

$$
\Delta T_{t}=G\left(\gamma, c, s_{t}\right) X_{q, t}+X_{o, t}+\varsigma_{t}
$$

$T_{t}$ is the tax base for PIT, CIT and VAT at time t. Next the vector $X_{q, t}=\hat{c}+\hat{\lambda}_{q} T_{t-1}+\hat{\theta}_{q}{ }^{\prime} T B_{t-i}+\sum_{i=1}^{p} \alpha_{i} \Delta T_{t-i}+\sum_{i=0}^{n} \hat{\phi}_{q}^{\prime} \Delta T B_{t-i}$ and

$$
X_{o, t}=\hat{c}+\hat{\lambda}_{o} T_{t-1}+\hat{\theta}_{o}{ }^{\prime} T B_{t-i}+\sum_{i=1}^{p} \alpha_{i} \Delta T_{t-i}+\sum_{i=0}^{n} \hat{\phi}_{o}{ }^{\prime} \Delta T B_{t-i} \text { where TB represents the various tax bases for }
$$

the wage bill, profits and consumption at time t.

This study follows Granger and Teräsvirta (1993) and Teräsvirta (1994) in making $\gamma$ dimension-free by dividing it by the variance of $\mathrm{c}$. To find the optimal values for $c$ and $\gamma$ that minimise the residual sum of squares, a grid search is conducted using the Broyden-Fletcher-Goldfarb-Shano (BFGS) algorithm.

\section{DATA AND EMPIRICAL EVIDENCE}

\section{Data Description}

South African quarterly data for the 1994q1-2009q3 period is used to estimate the tax elasticities. These elasticities are then used to calculate the structural budget balance. Government expenditure data can directly be downloaded from the South African Reserve Bank. For the wage bill, we use compensation of employees as a base for PIT. For profits, we use total gross operating surplus as a base for CIT. Consumption is used as the base for VAT. $^{2}$

Two sorts of tests for linearity are used. Table 2 provides the, Brock, Dechert and Sheinkman (BDS) (1987) test of any nonlinearity in the two models proposed by Girourd and André (2005). It tests whether the errors of the cointegrated model are correctly specified under the null of identically and independently distributed (i.i.d) errors against the alternative of an unspecified nonlinear process. The test can be used to test possible deviations from linear dependency or chaos. ${ }^{3}$ The results of different embedding dimensions and the standard deviations of the residuals are reported. The results in Table 2 clearly reject the null of linearity for the embedding dimensions for PIT, VAT and CIT. ${ }^{4}$

\footnotetext{
${ }^{4}$ Data can be directly downloaded from the South African Reserve Bank website. Codes are: Government expenditure (S47:4601m), compensation of employees (6240L), PIT (S-46:4570m), consumption (6007L) and VAT (S-46:4578m)

${ }^{3}$ Refer to Eviews 6 User's Guide for a more detailed discussion on the BDS test.

${ }^{4}$ Using different standard deviations yields the same conclusion.
} 
Table 2: BDS Test

\begin{tabular}{|l|l|l|l|}
\hline BDS test $\boldsymbol{\sigma}=\mathbf{0 . 0 5}$ & ResidProfits (P values) & ResidWageB (P values) & ResidCons (P values) \\
\hline Dimensions & 0.000 & 0.000 & 0.000 \\
\hline 2 & 0.000 & 0.000 & 0.000 \\
\hline 3 & ResidCIT (P values) & ResidPIT (P values) & ResidVAT (P values) \\
\hline Dimensions & 0.309 & 0.075 & 0.022 \\
\hline 2 & 0.000 & 0.000 & 0.011 \\
\hline 3 & & & \\
\hline
\end{tabular}

After having rejected that the model is linear, the next step is to apply the test by Teräsvirta (1994) in Escribano and Jordá (2001) to select the proper nonlinear functional form between a logistic transition regression and an exponential transition regression. Table 3, which provides the p-values for Teräsvirta's HO2 and HO3 tests, shows evidence in favour of LSTAR for PIT, CIT and VAT.

Table 3: Linearity Test

\begin{tabular}{|c|c|c|c|}
\hline \multicolumn{4}{|c|}{ Transition variable } \\
\hline Hypothesis & Wage bill (P values) & Profits (P values) & Consumption (P values) \\
\hline $\mathrm{H} 03$ & 0.97 & 0.45 & 0.58 \\
\hline $\mathrm{H} 02$ & 0.79 & 0.87 & 0.74 \\
\hline
\end{tabular}

For the recursive estimates, we estimate over fixed windows of data, where the first data window runs from 1994q1 to 2005q1, and each successive data window is extended by one observation; hence, the last data window runs from 2005 to 2009 (this setup delivers 20 expanding windows). From a policy point of view, this allows us to identify the evolution of the estimated model parameters over time and across regimes. We use sequences of expanding windows in which the sample size for estimation is increased by one observation in each successive window, as opposed to sequences of fixed-length rolling windows, simply because the larger (increasing) windows help the estimation procedures for the various models, which can be quite parameter intensive.

For robustness reasons, however, the exercise below also reports results based on a sequence of fixed-length rolling windows where each successive window is constructed by shifting the preceding window ahead by one observation. The rolling scheme can also be used to guard from moment or parameter drift due to the regime changes in fiscal policy, discussed in the preceding section; and on that basis, we believe it is worth comparing estimates from these two schemes. ${ }^{5}$

\section{EMPIRICAL EVIDENCE}

The results of the nonlinear estimates are compared to the results of Du Plessis and Boshoff (2008), Swanepoel and Schoeman (2002), Lizondo et al. (2006) and Jooste (2009). Their results are summarized in Table 4. The different methods yield marginally different results.

Table 5 includes the estimation results from our nonlinear regression. To calculate the expansion phase elasticity in the STR model (10), the sum of the linear and nonlinear part $\frac{\hat{\theta}_{q}}{-\hat{\lambda}_{q}}+\frac{\hat{\theta_{o}}}{-\hat{\lambda}_{o}}$, is taken. The results differ significantly from the linear estimates in Table 4 . The estimates indicate that strong asymmetries are present during the different phases of the cycle. During the upward phase of the cycle, a $1 \%$ increase in the wage bill, profits and

\footnotetext{
${ }^{5}$ It should be noted that there has been some debate on using recursive versus fixed-length rolling windows, mainly in the context of forecasting. On the expanding window versus fixed-length rolling window issue we note that according to Stock and Watson (2005, p. 26), "recursive forecasts are more accurate than the rolling forecasts" for the representative macroeconomic dataset they study. On the other hand, however, Giacomini and White (2006, p. 1566) find that a "rolling window procedure can result in substantial forecast accuracy gains relative to an expanding window for important economic time series."
} 
consumption, increases revenue collections by $1.87,2.77$ and 2.18 for PIT, CIT and VAT, respectively. Conversely, during the contraction phase of the cycle, revenue collection responds less than unity for PIT, CIT and VAT (though not significantly smaller than one). The elasiticities fall well within the range of elasticities reported in Table 4 when using equally weighted averages of the expansionary and contractionary elasticities for the various taxes. The nonlinear elasticities show that when the cycle suddenly turns, tax collections decrease quickly and by a lot. The results are robust in as much as the Hodrick-Prescott (H-P) output gap is also used. The VAT estimates are not significant in the H-P gap regression and barely significant in the SVAR gap regression. Most studies assume that this elasticity takes a value of one. The strong asymmetries just show how fast revenues could grow during an expansionary phase, which partly explains why the government consistently underestimates tax revenue. Government's expenditure decision can be greatly enhanced once these elasticities are incorporated, which would reduce overall surprises that might question the credibility of fiscal authorities.

Table 4: Linear Elasticities

\begin{tabular}{|l|l|l|l|l|}
\hline Taxes & Swanepoel et al. & Du Plessis et al. & Lizondo et al. & Jooste \\
\hline PIT & & & 1.43 & 0.84 \\
\hline CIT & & & 2.52 & 1.79 \\
\hline VAT & & 1.14 & 0.99 & 1.01 \\
\hline Income and profits & 1.04 & 1.05 & & \\
\hline Goods and services & 1.24 & & & \\
\hline
\end{tabular}

Table 5: Nonlinear Regression

\begin{tabular}{|c|c|c|c|c|c|c|}
\hline & PIT SVAR & PIT H-P & CIT SVAR & CIT H-P & VAT SVAR & VAT H-P \\
\hline \multicolumn{7}{|l|}{ Linear Part } \\
\hline \multicolumn{7}{|l|}{ Long run coefficient } \\
\hline \multirow[t]{2}{*}{$\mathrm{C}$} & $-1.88 * *$ & $-2.70 * * *$ & $-12.48 * * *$ & $-11.49 * * *$ & $-8.32 * *$ & -2.89 \\
\hline & [2.91] & {$[0.65]$} & {$[2.91]$} & [3.85] & {$[3.59]$} & [2.84] \\
\hline \multirow{2}{*}{$\hat{\lambda_{o}}$} & $-0.26 * *$ & $-0.35 * * *$ & $-0.31 * *$ & $-0.24 * *$ & $-0.16^{*}$ & -0.17 \\
\hline & {$[0.11]$} & {$[0.12]$} & [0.13] & [0.11] & [0.08] & [0.12] \\
\hline \multirow{2}{*}{$\hat{\theta_{o}}$} & $0.23 * *$ & $0.21 * * *$ & $0.27 * *$ & $0.21 * *$ & $0.14 *$ & 0.14 \\
\hline & {$[0.10]$} & {$[0.11]$} & {$[0.11]$} & [0.09] & {$[0.07]$} & {$[0.10]$} \\
\hline \multicolumn{7}{|l|}{ Nonlinear Part } \\
\hline \multirow{2}{*}{$\hat{\lambda}_{q}$} & $-1.30 * *$ & $-1.46 * * *$ & $-0.81 * *$ & $-0.92 * *$ & $-1.25^{*}$ & -0.46 \\
\hline & {$[0.63]$} & {$[0.40]$} & {$[0.31]$} & {$[0.37]$} & {$[0.64]$} & {$[0.52]$} \\
\hline \multirow{2}{*}{$\hat{\theta_{q}}$} & $1.24 * *$ & $1.48 * * *$ & $1.54 * * *$ & $1.65 * * *$ & $1.65 * *$ & 0.62 \\
\hline & {$[0.58]$} & {$[0.39]$} & {$[0.47]$} & {$[0.56]$} & {$[0.79]$} & {$[0.63]$} \\
\hline \multicolumn{7}{|l|}{ Upward phase } \\
\hline$\frac{\hat{\theta}_{q}}{-\hat{\lambda}_{q}}+\frac{\hat{\theta_{o}}}{-\hat{\lambda}_{o}}$ & 1.87 & 1.89 & 2.77 & 2.67 & 2.18 & 2.17 \\
\hline \multicolumn{7}{|l|}{ Downward phase } \\
\hline$\frac{\hat{\theta_{o}}}{-\hat{\lambda}_{o}}$ & 0.88 & 0.89 & 0.86 & 0.88 & 0.81 & 0.82 \\
\hline$R^{2}$ & 0.63 & 0.73 & 0.57 & 0.52 & 0.33 & 0.49 \\
\hline SE & 0.07 & 0.07 & 0.22 & 0.24 & 0.09 & 0.09 \\
\hline \multirow[t]{2}{*}{ JB } & 1.39 & 1.42 & 0.52 & 1.62 & 1.34 & 22.17 \\
\hline & $(0.49)$ & $(0.49)$ & $(0.77)$ & $(0.30)$ & $(0.52)$ & $(0.00)$ \\
\hline Heteroskedasticity & $(0.17)$ & $(0.54)$ & $(0.51)$ & $(0.18)$ & $(0.28)$ & $(0.01)$ \\
\hline Serial Correlation & $(0.94)$ & $(0.98)$ & $(3.49)$ & $(0.12)$ & $(0.25)$ & $(0.70$ \\
\hline Model AIC & -2.46 & -2.70 & -0.11 & 0.10 & -1.73 & -1.32 \\
\hline
\end{tabular}

Note: Parenthesis represents probability values and block parenthesis are standard errors. $*, * *, * * *$ denote significance levels at 10, 5 and 1 percent. One lag was used for the serial correlation test. 
The Journal of Applied Business Research - July/August 2011

Volume 27, Number 4

Fixed and rolling estimates were used to characterize the nonlinear estimates (equation 7) for 12 periods. The first row of Figures 1 and 2 is the nonlinear coefficients for the expansive phase and the second row is the contraction phase medium run coefficients. The nonlinear estimates in Figure 2 are constant over time. This suggests that correctly capturing asymmetries in the economy yields robust and invariant estimates.

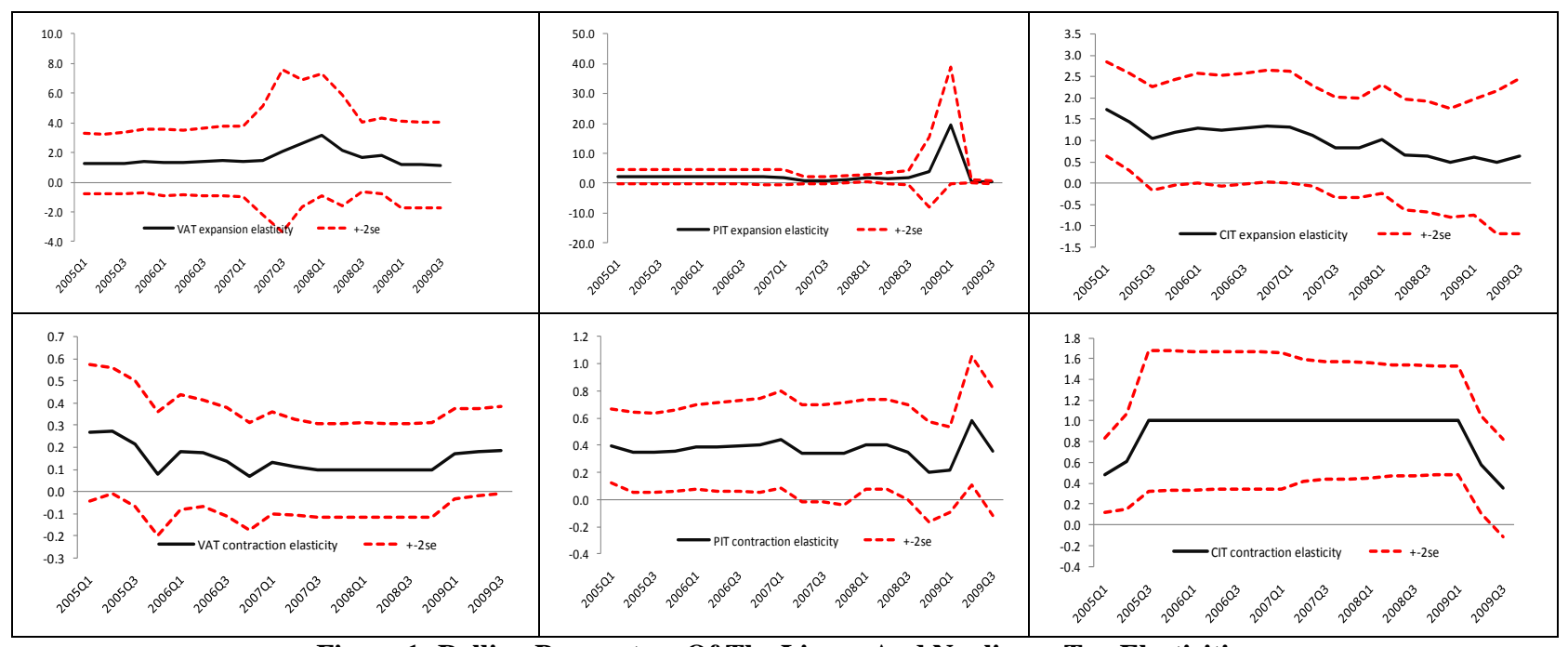

Figure 1: Rolling Parameters Of The Linear And Nonlinear Tax Elasticities

Note: The black lines are the estimated fixed window rolling coefficients. The dashed lines represent standard errors

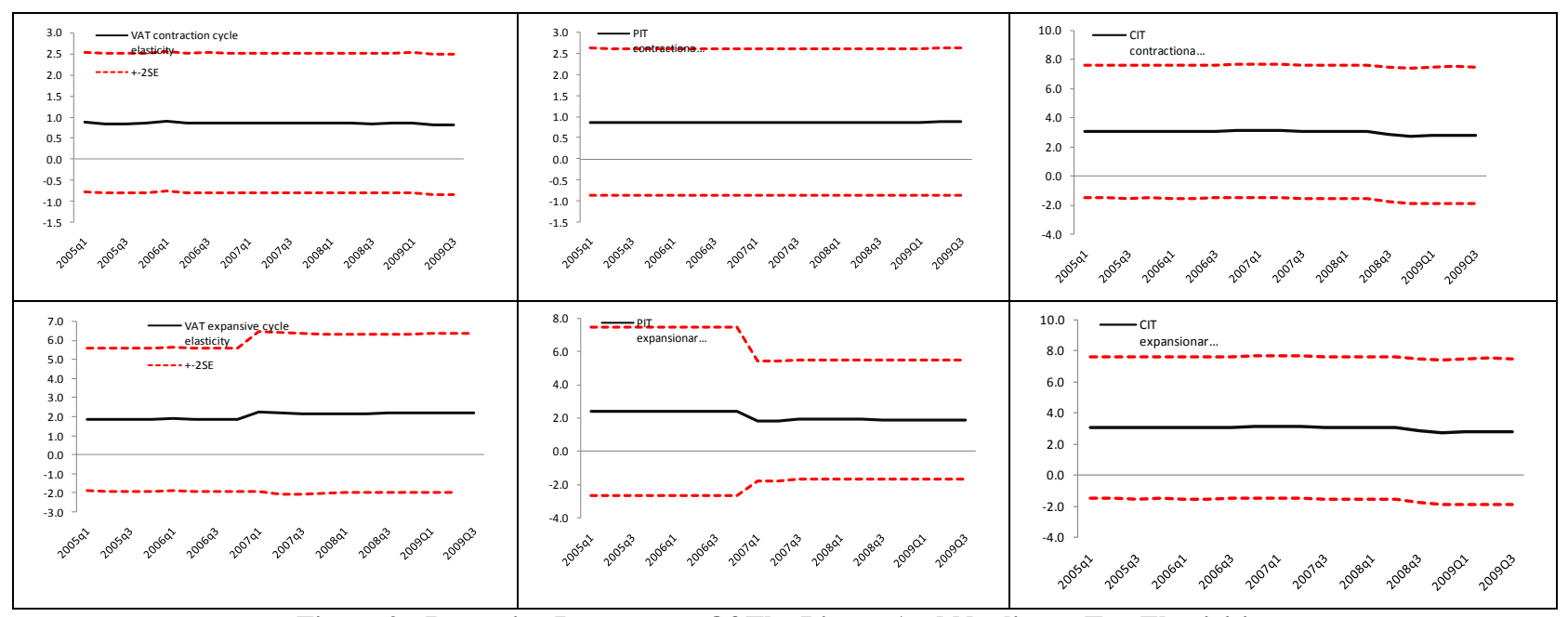

Figure 2: Recursive Parameters Of The Linear And Nonlinear Tax Elasticities

Note: The black lines are the estimated fixed window rolling coefficients. The dashed lines represent standard errors

Moving into South Africa's longest contraction since the 1989-1993 period, policy makers should make additional precautions regarding the expenditure framework. What Figure 3 suggests is that the economy still has to purge itself from cyclical effects in order to have a conventional budget (CBB) that is in line with the structure of the economy. The difference in using the downward phase and upward phase elasticity is more than one per cent of GDP (close to R 30 bn); ie. as the cycle is correcting itself, we will have close to R30 bn less to spend on the economy. Using the wrong elasticities would lead to a policy belief that there is an additional R30 bn to spend during the downward phase of the cycle.

122

(C) 2011 The Chute Institute 


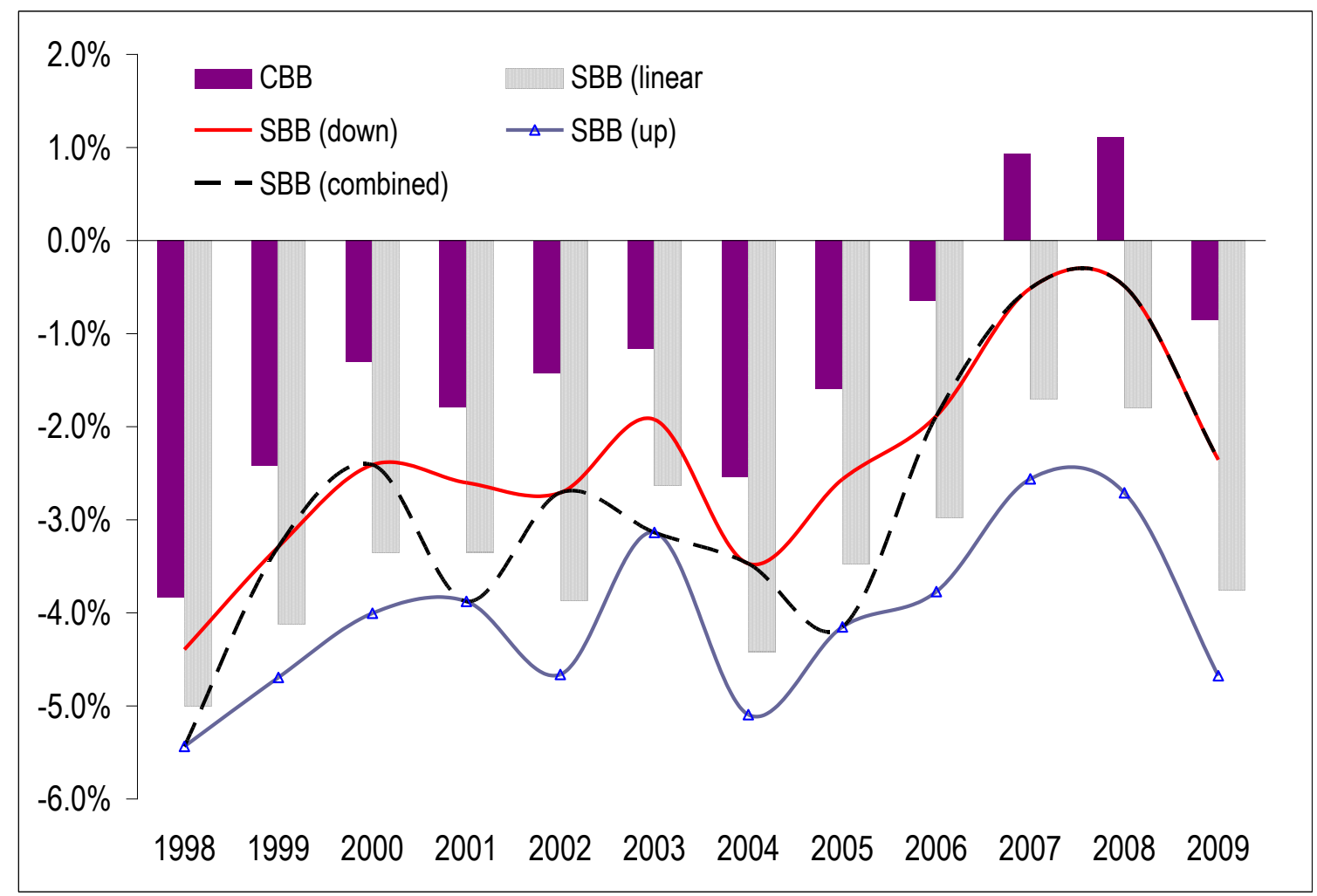

Figure 3: The SBB incorporating Different Coefficients Over The Cycle

Note: SBB is as a percentage of potential GDP and CBB is as a percentage of nominal GDP

\section{CONCLUSION AND POLICY IMPLICATIONS}

This paper discusses two important issues regarding tax elasticities, the first being whether taxes respond symmetrically over the cycle and the second being whether tax elasticities are constant and stable over time. To answer these questions, we test for and estimate possible asymmetries through incorporating a nonlinear framework. The weighted averages of the nonlinear estimates are similar to those of other studies. However, the nonlinear estimates showed that tax collections indeed move asymmetrically over the cycle. This has significant implications for policy making in using the structural budget balance as a gauge for the overall fiscal stance. The study shows that applying these elastcities can lead to large differences in the structural budget balance. Fiscal hawks argue that fiscal austerity measures should be implemented as the global economy recovers. The estimates obtained in this study should serve as a tool in assessing future revenue collections and, hence, overall expenditures. These elasticities should guide policy makers' decisions to ensure that expenditures will be met by revenue streams in the future and serve as an illuminating path to improved policy making.

These estimates could well be affected by other factors that could possible bias the results. As a further line of research, estimating efficiency gains from the South African Revenue Services through improvements in tax collection and the underwriting of tax laws could render more accurate estimates.

\section{ABOUT THE AUTHORS}

Charl Jooste is a senior economist at the South African National Treasury. My work and research interests are focused on applying econometrics in the study of fiscal policy objectives. Other research work undertaken includes modelling uncertainty in debt dynamics and fiscal sustainability. Graduate Student, Department of Economics, University of Pretoria, Pretoria, 0002, South Africa. 
Ruthira Naraidoo is currently a Senior Lecturer at the Department of Economics, University of Pretoria. I have completed my Ph.D. in 2004 from the Department of Economics, Cardiff University and have worked as a lecturer in economics at the Department of Economics, Keele University and University of Nottingham, Ningbo. I secured my BSc (Honours) degree from University of Mauritius and MSc degree from Cardiff University. My research interests are in the areas of applied macroeconomic theory and policy with focus on monetary economics, labour economics and time series econometrics. I have published in international and domestic journals. Department of Economics, University of Pretoria, Pretoria, 0002, South Africa.

\section{REFERENCES}

1. Blanchard, O. \& Perotti, R. 1999. An empirical characterization of the dynamic effects of changes in government spending and taxes on output. NBER working paper 7269. [Online] Available from: http://www.nber.org/papers/w7269.

2. Blanchard, O \& Quah, D. 1989. The dynamic effects of aggregate demand and aggregate supply disturbances. American Economic Review, 79, 655-673.

3. Brock, W., W. Dechert, \& J. Scheinkmann. 1987. A test for independence based on the correlation dimension. Working Paper, University of Wisconsin at Madison.

4. Du Plessis, S. \& Boshoff, W. 2007. A fiscal rule to produce countercyclical fiscal policy in South Africa. Stellenbosch economic working papers:13/07.

5. Du Plessis, S. A., B. W. Smit and F. Sturzenegger 2007. Identifying Aggregate Supply and Demand Shocks in South Africa. Stellenbosch, Mimeograph.

6. $\quad$ Enders, W. 2004. Applied econometric time series. $2^{\text {nd }}$ ed. United States of America: Wiley \& Sons.

7. Escribano, A \&Jordá, O. 2001. Testing nonlinearity: Decision rules for selecting between logistic and exponential STAR model. Spanish Economic Review, 3, 193-209.

8. $\quad$ Franses, P.H.\& van Dijk, D. 2000.Non-linear time series models in empirical finance. $6^{\text {th }}$ ed. New York: Cambridge University Press.

9. Girourd, A. \& André, C. 2005. Measuring cyclically adjusted budget balances for OECD countries. OECD Economic department working papers: 2005/21.

10. Hagemann, R. 1999. The Structural Budget Balance: The IMF's methodology. IMF Working paper.

11. Hodrick, R. J. \& Prescott, E. C. 1997. Postwar U.S. business cycles: an empirical investigation. Journal of Money, Credit, and Banking, 29, 1-16.

12. Johansen, S. 1992. Cointegration in partial systems and the efficiency of single equation analysis. Journal of Econometrics, 52, 389-402.

13. Jooste, C. 2009. Estimating tax elasticities: The case for Corporate Income Tax, Personal Income Tax and Value Added Tax. [Online] Available from: www.africametrics.org/documents/conference09/papers/Jooste.pdf

14. Lizondo, S., Cuevas, A., Harjes, T., Shirono, K., Debrun, X., Lukonga, I., \&Nkusu, M. 2006. South Africa: Selected issues. International Monetary Fund country report: 2006/328.

15. Lutkepohl, H. \& Kratzig, M. 2004. Applied time series econometrics. New York: Cambridge University Press.

16. Pesaran, M.H. \& Shin, Y. 1998. An autoregressive distributed lag modelling approach to cointegration analysis. Econometrics and economic theory in the $20^{\text {th }}$ century. The Ragner Frisch centennial symposium (S. Strom, ed.), 371-413.

17. Swanepoel, A. 2007. Adjusting South Africa's fiscal balance for terms of trade effects. South African Journal of Economics, 75, 719-727.

18. Swanepoel, A.S. \& Schoeman, N.J. 2002. Tax revenue as an automatic fiscal stabiliser: A South African perspective. South African Journal of Economics, 5, 566-588.

19. Teräsvirta, T., 1994. Specification, estimation, and evaluation of smooth transition autoregressive models. Journal of the American Statistical Association 89, 208-218.

20. Tong, H. \& Lim, K.S. 1980. Threshold autoregressions, limit cycles and data. Journal of the Royal Statistical Society, 42, 245-292.

21. Turner, D. Should measures of fiscal stance be adjusted for terms of trade effects? OECD Economic department working papers: 2006/47. 
22. Van Rensburg, T. \& Simmonds, M. 2007 A technical note on the structural budget balance estimate. National Treasury working paper.

23. Wickens, M. R. \& T.S. Breusch., 1988. Dynamic Specification, the Long-Run and the Estimation of Transformed Regression Model. The Economic Journal, 98, 189-205

24. Wolswijk, G. 2007. Short and long run tax elasticities: The case of the Netherlands. European Central Bank working papers: 2007/763. 


\section{$\underline{\text { NOTES }}$}

